\title{
Technological Competencies: A Study on the Acceptance of Digital Technology on Vocational Teachers in Indonesia
}

\author{
Farid Mutohhari ${ }^{1}$, Herminarto Sofyan ${ }^{2}$, Muhammad Nurtanto ${ }^{3}$ \\ Postgraduate Program of Technology and Vocational Education, Yogyakarta State \\ University $^{1,2}$, Department of Mechanical Engineering Education, Faculty of Mechanical \\ Engineering Education, Universitas Sultan Ageng Tirtayasa ${ }^{3}$
}

\{faridmutohhari.2020@student.uny.ac.id¹,hermin@uny.ac.id², mnurtanto23@untirta.ac.id ${ }^{3}$ \}

\begin{abstract}
Changes in the flow of globalization are influenced by the presence of the Industrial Revolution 4.0, including the role of digital technology (DT) in the education sector, namely cyber technology-based learning. The main challenge for vocational teachers is the mastery of skills in learning using DT. The acceptance of DT is categorized into five clusters, namely awareness, literacy, capability, creativity, and criticism adapted from Pavlova's. The study was conducted to measure the level of ability of productive class vocational teachers. The study approach used quantitative with descriptive statistical analysis. A total of 50 productive classroom teachers in Yogyakarta were involved in filling out a questionnaire that had been tested and validated by content, experts, and calculation of product-moment correlation. The results of the study show (1) technological awareness 83.08\%; (2) technological literacy $66.32 \%$; (3) technological capability of $39.28 \%$; (4) technological creativity of $21.92 \%$; and (5) technological criticism at $20.84 \%$. The use of DT is clearly in the low category and shows the capacity of vocational teachers needs to be improved. Training programs, self-development, and motivation are important factors in improving digital technology skills.
\end{abstract}

Keywords: Industrial Revolution 4.0; Technology Acceptance Level; Digital Technology; Vocational Teachers

\section{Introduction}

During the Industrial Revolution 4.0, digital transformation (DT) occurred mainly in all areas, including education [1]-[4]. Changes in the educational age have disrupted traditional learning methods and models and replaced them with new learning models based on digital technology [5]-[7]. We have to respond quickly and take concrete steps to solve the problems that arise and harmonize the changes and challenges that exist. The main objective is to improve the quality of learning from the alignment of infrastructures, human resources, in other words, teachers who are adaptive and capable of the latest digital technologies. 
Changes are happening very quickly, and solutions need to be found. Then the question RQ1 arises: "Is the teacher who is an agent of change and plays the role of facilitator of learning in the classroom ready to face the challenges of education 4.0?"., RQ2: "How to use internet-based digital technology to support the learning process in education 4.0?". Thus, there is a need to study the teachers' ability to use TD effectively for learning. Thus, the resulting graduates have skills consistent with 21 st-century work requirements [8].

Digital transformation based on cybersecurity (TDC) and is in line with the conceptual industrial revolution 4.0 [9], [10]. The development of eLearning models in terms of concept and implementation is increasingly based on the latest available technologies. There are clear reasons for the massive integration of information and communication technologies for learning. The digitization of the production process in the world of work which is often called Industrial Cyber-Physical Systems (ICPS) requires high competence in mastering information and communication technology, which is the fundamental reason for the integration of ICT technology in the learning process. The world of work, of course, wants a change in the method and process of technology that is more effective and efficient with more comprehensive digitalization in almost all areas of the production process, the aim of which is to improve the quality of products and increase incomes. The transformation of ICT-based learning in a comprehensive and precise manner in the learning process is believed to be able to overcome the problem of digitalization in the business world regarding employment, especially in vocational schools.

Vocational education is education for the world of work. The aim of vocational education is to equip individuals with skills whose origin is to meet the needs of life so that it becomes one of the conditions for economic prosperity [11]. Then [12] added that vocational education should have the main objective of the job to prepare its graduates well for the labor market in the future. Thus, it can be said that vocational education must have the power and capability to adapt to the development of industrial revolution 4.0.

The competency development of human resources to answer the challenges of competing in the world of work currently focuses on developing vocational education which is education for the world of work. The focus of the development of vocational education is to transform learning in vocational high schools. One of the changes was that initially the learning process was carried out directly face-to-face which was changed to blended learning, namely by integrating the e-learning system by integrating ICT technology in the learning process [13], [14]. In addition, the application of facilities and infrastructure to support the learning process based on cyber-physical systems is expanding to support the smooth learning process.

The achievement of the quality of online learning is influenced by several factors, including the teacher, who in this case becomes the facilitator of student learning. Teachers are required to master internet-based digital technology, with various learning applications on it so that it can facilitate students to learn creatively with time effectiveness and efficiency, which in turn can improve the quality and learning outcomes. Teachers who do not care about the development of digital technology will not be able to understand and feel the benefits of this technology to support learning using the e-learning model. Then teachers who are not digitally literate properly will find it difficult to apply digital technology for learning, where learning will be stagnant and will not develop better.

The ability of teachers to use digital technology has a level of acceptance called the technology competency taxonomy. According to [15], there are five levels in the taxonomy of technological competence, namely: (1) technological awareness at the first or lowest level whose conditions are limited to knowing technology; (2) technological literacy at the second level whose condition has a deep understanding of the use and benefits of technology; (3) 
technological capability at the third level which is the competence in using technology appropriately; (4) technological creativity at the fourth level which is the ability to find new technologies to solve problems, and; (5) Technological criticism at the highest level, which is the ability to assess and make appropriate and critical decisions regarding a choice of technological findings to be used.

The extent to which the five levels of acceptance of digital technology have been achieved in the taxonomy of technology competence in vocational teachers really needs to be analyzed and disclosed to provide information on where the position or percentage is the highest of the five levels. The results of the study conducted to make recommendations in mapping training for productive teachers that are appropriate in terms of increasing competence in the use of digital technology to support e-learning learning in Indonesia.

Based on the results of a preliminary study on the implementation of e-learning, it was found that the learning process in several vocational high schools is only one way, namely sending the subject matter into a group according to the subject. There is a very limited process of interaction, discussion, and direct participation of teachers and students. Based on the findings of these observations, a simple interview was held to see the causes of these problems. The results of interviews conducted by several professional teachers revealed certain perceptions that "teachers are not well trained in the use of Internet-based digital technology to implement e-learning". Some teachers are not familiar with the development of digital technology and some teachers are familiar with its development but are unable to exploit or apply digital technology on the Internet for learning.

Starting from the problems and the results of these observations are increasingly clear that educators who function as facilitators in e-learning must receive training in the use of digital technology. Therefore, the problems arising from the observational findings are only to a limited level. Therefore, to get an accurate picture of teacher training needs, it is necessary to conduct research on a broader scale with a sample that can represent the existing teacher population. Therefore, the main objective of this study is to analyze the acceptance rate of digital technology for professional education teachers.

\section{Methodology}

The study used a quantitative approach with descriptive statistical analysis [16]. Quantitative shows the score and percentage of each level of acceptance of digital technology. The research was conducted in six Vocational High Schools in Yogyakarta Province. Data were collected during November 2020. As many as 50 teacher respondents as productive class teachers were actively involved in filling out the instruments.

The data collection approach used a questionnaire technique. The questionnaire in this study is a closed questionnaire that uses a statement containing the responses provided. The number of surveys is 50 per digital technology acceptance level, for a total of 10 surveys. The formulation of the questionnaire instrument was organized based on a matrix containing indicators for each level of acceptance of digital technology. The questionnaire used has four alternative answers (5 Likert) [17], consisting of Strongly Agree (SA), Agree (A), Undecided (U), Disagree (D), and Strongly Disagree (SD) with a score pattern of 5-4 -3-2-1. Instrument validation uses expert judgment and product-moment correlation to obtain power from the elements on the instrument.

The data analysis technique uses descriptive analysis techniques which are intended to measure the amount of the score and the percentage of each acceptance level of digital 
technology. The criteria for drawing conclusions from the results of data analysis are based on the following five indicators:

Table 1. Decision Making Criteria Based on Percentage and Category

\begin{tabular}{lc}
\hline Category & Percentage range \\
\hline Strongly Agree & $81.00 \%-100.00 \%$ \\
Agree & $61.00 \%-80.00 \%$ \\
Undecided & $41.00 \%-60.00 \%$ \\
Disagree & $21.00 \%-40.00 \%$ \\
Strongly Disagree & $1.00 \%-20.00 \%$ \\
\hline
\end{tabular}

\section{Result and Discussion}

The collected data were grouped and analyzed using SPSS V.21 software. The results of the analysis are presented in the form of a chart diagram, then the data is interpreted descriptively describing the meaning of the data. Acceptance rate considers minimum data, maximum data, mean, and Std. Dev. The last stage is the decision from the acquisition of an average value into the category. In detail, the level of acceptance of digital technology developed by Pavlova's and tested on vocational teachers in the automotive field in Yogyakarta is as follows:

\subsection{Level 1 - Technological Awareness (TA)}

The research data on the level of care for digital technology obtained through a questionnaire instrument with a total of 10 statement items had a minimum score of 37 and a maximum score of 47 . The total score obtained was 2,070, an average of 41,54, a standard deviation of 2,697, the median amounting to 41 , and modes of 41 , with an average percentage of $83.08 \%$. The data description and frequency distribution are shown in the following histogram.

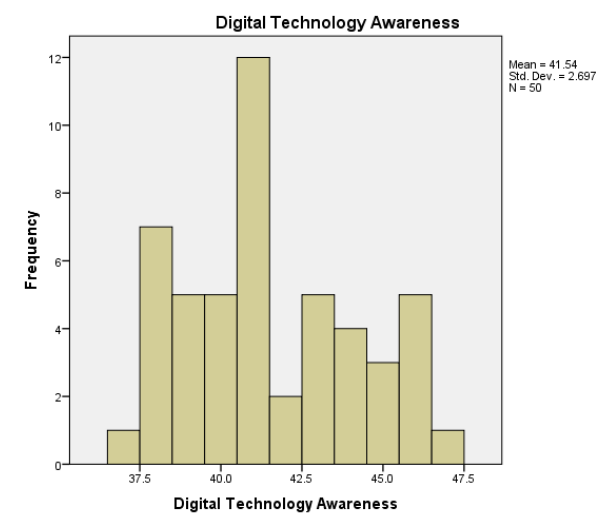

Fig. 1. Technological Acceptance of Competence at the Awareness Level

While the frequency distribution based on the value category includes: (1) as many as 37 respondents had a very high category score; (2) as many as 13 respondents have a high category score; and (3) there are no respondents who have moderate, low, and very low 
category scores. The frequency distribution based on the value category is shown in the frequency distribution table.

Table 2. Distribution of Frequency of Technology Competence on Awareness

\begin{tabular}{lcccc}
\hline & Frequency & Percent & Valid Percent & Cumulative Percent \\
\hline Highest & 37 & 74.0 & 74.0 & 74.0 \\
High & 13 & 26.0 & 26.0 & 100.0 \\
Total & 50 & 100.0 & 100.0 & \\
\hline
\end{tabular}

Based on the results obtained, the total score is 2,077 and an average of 41,54 with a percentage of $83.08 \%$, it shows that the results are in the percentage score range of $81.00 \%$ $100.00 \%$ with a very high category. Thus, it can be concluded that vocational teachers have a very high level of care for technological competencies, especially digital technology.

Very competency can be achieved if it is supported and based on knowledge. Meanwhile, knowledge can be owned if it is supported by curiosity and a sense of care for knowledge. Concern for digital technology is a starting point or basis for building knowledge and understanding [15]. This means that without having a concern for digital technology, knowledge, and understanding of digital technology will not be formed or biting a person. Conversely, having a concern for the development of digital technology will shape knowledge and understanding of these technologies. [18] Teachers as learning innovators in the classroom must gradually build awareness of emerging digital technologies. Starting from caring then it will be literate, conversely, if you do not awareness about digital technology, it will not be digitally literate.

\subsection{Level 2 - Technological Literacy (TL)}

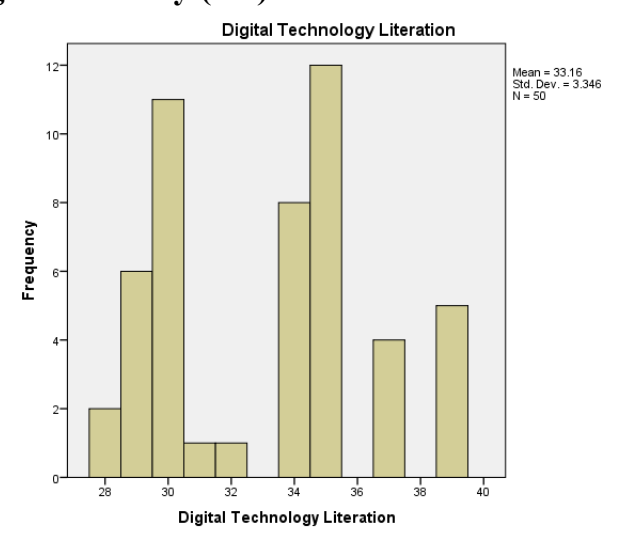

Fig. 2. Acceptance of Technology Competence at Literacy Level

The research data at the digital technology literacy level were obtained through a questionnaire instrument with a total of 10 statements having a minimum score of 28 and a maximum score of 39 . The total score obtained was 1,658 , the average was 33.16 , the standard deviation was 3,346 , the middle value was 34 mode 35 , with an average percentage of $66.32 \%$. The data description and frequency distribution are shown in the following histogram.

Meanwhile, the frequency distribution based on the value category includes: (1) there are no respondents who have a very high category score; (2) 29 respondents have a high category 
score; (3) as many as 21 respondents had a moderate score; and (4) there are no respondents who have low and very low category scores. The frequency distribution based on the value category is shown in the frequency distribution table. The frequency distribution based on the value category is shown in the frequency distribution table.

Table 3. Frequency Distribution of Technology Competence in Literacy

\begin{tabular}{lcccc}
\hline & Frequency & Percent & Valid Percent & Cumulative Percent \\
\hline Highest & 29 & 58.0 & 58.0 & 58.0 \\
High & 21 & 42.0 & 42.0 & 100.0 \\
Total & 50 & 100.0 & 100.0 & \\
\hline
\end{tabular}

Based on the results obtained, the total score is 1,658 and the average is 33.16 with a percentage of $66.32 \%$, it shows that these results are in the range of percentage scores of $61 \%$ $-80 \%$ in the high category. Thus, it can be concluded that vocational teachers have a high level of digital technology literacy.

Understanding digital technology can affect a person's ability to use or operate digital technology [19]. A comprehensive understanding of technology is at the core of technological literacy [15]. This means that digital literacy can affect the ability to use digital technology. This digital literacy is very important to be built in a teacher as a basis for applying his understanding in the practice of using digital technology in learning. Without digital literacy, capabilities in using digital technology will not be developed [18].

Vocational teachers in managing online learning are required to have high digital literacy. Vocational teachers must be able to comprehensively understand the functions, uses, benefits, and effects or impacts of digital technology in supporting the learning process, especially in carrying out e-learning. This of course requires understanding and considering the wider benefits and impacts of digital technology called digital literacy [20].

\subsection{Level 3 - Technological Capability (TCa)}

The research data at the level of digital technology capability obtained through a questionnaire instrument with a total of 10 statement items had a minimum score of 16 and a maximum score of 30 . The total score obtained was 982, the average was 19.64 , the standard deviation was 3,837 , the middle value was 19 , mode 16 , with an average percentage of $39.28 \%$. The data description and frequency distribution are shown in the following histogram.

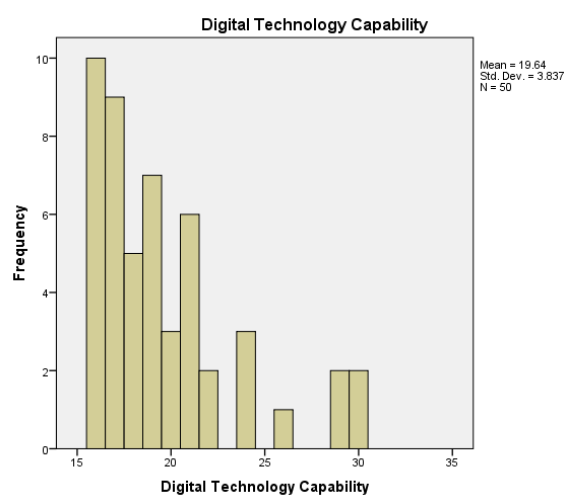

Fig. 3. Acceptance of Technology Competence at the Capability Level 
While the frequency distribution based on the value category includes: (1) there are no respondents who have very high and high category scores; (2) 4 respondents had a moderate score; (3) as many as 15 respondents have a low category score, and (4) as many as 31 respondents had a very low category score. The frequency distribution based on the value category is shown in the frequency distribution table.

Table 4. Frequency Distribution of Technological Competence on Capability

\begin{tabular}{lcccc}
\hline & Frequency & Percent & Valid Percent & Cumulative Percent \\
\hline Highest & 4 & 8.0 & 8.0 & 8.0 \\
High & 15 & 30.0 & 30.0 & 38.0 \\
Total & 31 & 62.0 & 62.0 & 100.0 \\
\hline
\end{tabular}

Based on the results obtained, the total score is 982 and the average is 19.64 with a percentage of $39.28 \%$, it shows that these results are in the range of percentage scores of $21.00 \%-40.00 \%$ with a low category. Thus, it can be concluded that vocational teachers have a low level of capability or ability to use digital technology.

The results of this study indicate that the ability of vocational teachers to use digital technology is still low and still requires improvement or improvement incompetence. [21] revealed the challenges that caused digital competence not to be mastered properly by teachers or students. One of the reasons is the lack of training related to the use of appropriate digital technology in learning.

The acceptance of digital technology for teachers, especially vocational teachers in the era of digital transformation is very important. Vocational teachers should integrate digital technology in the learning process for learning effectiveness [9]. The success in integrating digital technology is very much determined by the users or operators, in this case, teachers and students. Teachers, especially as educators as well as learning facilitators, must be able to use or operate digital technology in learning.

The level of the teacher's ability to use digital technology can also be used as a basis for being able to develop innovation and creativity in using digital technology. This is because, in stages, creativity is above the level of capability. In other words, the basis for building creativity in using digital technology is the ability to use digital technology [15].

\subsection{Level 4 - Technological Creativity (TCr)}

Research data on the level of digital technology creativity obtained through a questionnaire instrument with a total of 10 statement items had a minimum score of 10 and a maximum score of 17 . The total score obtained was 548, an average of 10.96, a standard deviation of 1.958 , a mean value of 10 , mode 10 , with an average percentage of $21.92 \%$. The data description and frequency distribution are shown in the following histogram. 


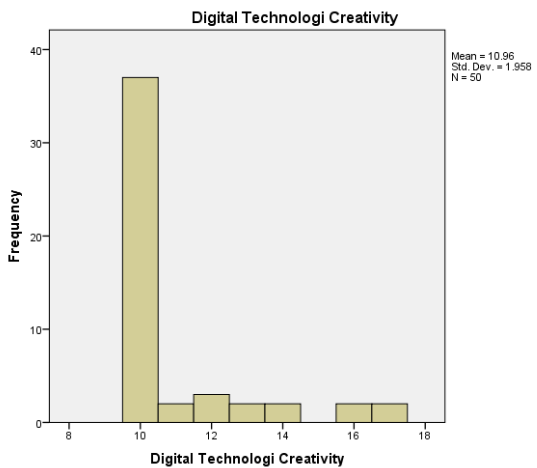

Fig. 4. Acceptance of Technology Competencies at the Creativity Level

Meanwhile, the frequency distribution based on the value category includes: (1) there are no respondents who have very high, high, medium, and low category scores; and (2) 50 or all respondents have a very low category score. The frequency distribution based on the value category is shown in the frequency distribution table.

Table 5. Frequency Distribution of Technology Competencies in Creativity

\begin{tabular}{ccccc}
\hline & Frequency & Percent & Valid Percent & Cumulative Percent \\
\hline Lowest & 50 & 100.0 & 100.0 & 100.0 \\
\hline
\end{tabular}

Based on the results obtained, the total score is 548 and an average of 10.98 with a percentage of $21.92 \%$, it shows that these results are in the range of percentage scores of $21.00 \%-40.00 \%$ with a low category. Thus, it can be concluded that vocational teachers have a low level of creativity in using digital technology.

Creativity in using digital technology, creating new innovations in digital technology for learning is very much needed, given the digital transformation we are currently facing. Creativity in this era will certainly lead to or be related to digital technology [10]. This technology will provide space for users to realize new innovations through various digital devices, digital platforms, and other digital applications. However, this is the biggest challenge in making appropriate and useful innovations to support the production process, in this case also includes the learning process [22].

\subsection{Level 5 - Technological Criticism (TCm)}

Research data at the critical level of digital technology were obtained through a questionnaire instrument with a total of 10 statement items having a minimum score of 10 and a maximum score of 15 . The total score obtained was 521, the average was 10.42 , the standard deviation was 1.144 , the middle value was 10 , mode 10 , with an average percentage of $20.84 \%$. The data description and frequency distribution are shown in the following histogram. 


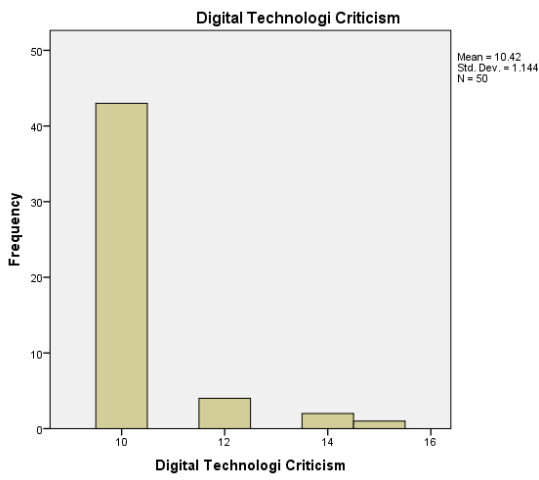

Fig. 5. Acceptance of Technology Competence at the Criticism Level

Meanwhile, the frequency distribution based on the value category includes: (1) there are no respondents who have very high, high, medium, and low category scores; and (2) 50 or all respondents have a very low category score. The frequency distribution based on value categories is also shown in the frequency distribution table.

Table 6. Frequency Distribution of Technology Competencies in Criticism

\begin{tabular}{ccccc}
\hline & Frequency & Percent & Valid Percent & Cumulative Percent \\
\hline Lowest & 50 & 100.0 & 100.0 & 100.0 \\
\hline
\end{tabular}

Based on the results obtained, the total score is 521 and an average of 10.42 with a percentage of $20.00 \%$, it shows that the results are in the percentage score range of $1.00 \%$ $20.00 \%$ with a very low category. Thus, it can be concluded that vocational teachers have a very low level of criticality in using digital technology.

Critical thinking is high-level thinking about something that can provide all the benefits with its effectiveness and efficiency. Effectiveness and efficiency can certainly be seen and felt the benefits after a person does an activity which is the result of his critical thinking [23]. Critical thinking in using digital technology is very important to do. The effectiveness and efficiency of a digital technology can be seen and felt when we are able to be critical of the technology. The critical level can be seen if a person has been able to use based on his judgment and his opinion correctly about the benefits, uses that can drive the effectiveness and efficiency that will be obtained when using a digital technology to achieve the goals he wants [15].

\section{Conclusion}

This study recommends that the highest level of digitalization technology competence in vocational teachers is technology care at $83.08 \%$, while the higher the level of technology there is a decrease in knowledge which indicates that the teacher's technological competence is in a very low category. Some of the causes of low technology are the involvement of vocational teachers in classroom learning and limited laboratories using digital. Researchers recommend increasing vocational teachers through training programs, knowledge sharing, and self-awareness in following global changes. 


\section{References}

[1] Z. Arifin, M. Nurtanto, A. Priatna, N. Kholifah, and M. Fawaid, 'Technology Andragogy Work Content Knowledge Model as a New Framework in Vocational Education: Revised Technology Pedagogy Content Knowledge Model', TEM J., vol. 9, no. 2, pp. 786-791, May 2020, doi: 10.18421/TEM92-48.

[2] C. Bagnoli, F. Dal Mas, and M. Massaro, 'The 4th Industrial Revolution', Int. J. EServ. Mob. Appl., 2019, doi: 10.4018/ijesma.2019070103.

[3] K. Schwab, The Fourth Industrial Revolution. Geneva: World Economic Forum, 2016.

[4] A. A. Shahroom and N. Hussin, 'Industrial Revolution 4.0 and Education', Int. J. Acad. Res. Bus. Soc. Sci., 2018, doi: 10.6007/ijarbss/v8-i9/4593.

[5] Z. Arifin, M. Nurtanto, W. Warju, R. Rabiman, and N. Kholifah, 'The TAWOCK conceptual model at content knowledge for professional teaching in vocational education', Int. J. Eval. Res. Educ. IJERE, vol. 9, no. 3, Art. no. 3, Sep. 2020, doi: 10.11591/ijere.v9i3.20561.

[6] P. Sharma, 'Digital Revolution of Education 4.0', Int. J. Eng. Adv. Technol., vol. 9, no. 2, pp. 3558-3564, 2019, doi: 10.35940/ijeat.a1293.129219.

[7] V. Puncreobutr, 'Education 4.0: New Challenge of Learning', J. Humanit. Soc. Sci., 2016.

[8] B. Trilling and C. Fadel, 21st Century Skills: Learning for Life in Our Times. San Francisco: Jossey-Bass, 2009.

[9] A. Aziz Hussin, 'Education 4.0 Made Simple: Ideas For Teaching', Int. J. Educ. Lit. Stud., 2018, doi: 10.7575/aiac.ijels.v.6n.3p.92.

[10] Gunadi, H. Sofyan, M. Nurtanto, Z. Arifin, and P. Sudira, 'Vocational Teachers Readiness in Face of the Industrial Revolution 4.0: Vocational Teachers Perceptions in Yogyakarta-Indonesia', J. Phys. Conf. Ser., vol. 1700, p. 012082, Dec. 2020, doi: 10.1088/1742-6596/1700/1/012082.

[11] L. Clark and C. Winch, Vocational Education: International Approaches, Developments and Systems. New York: Routledge, 2007.

[12] P. Matthias, The Future of Vocational Education and Training in a Changing World. Berlin: Springer VS, 2012.

[13] N. Kholifah, P. Sudira, R. Rachmadtullah, M. Nurtanto, and S. Suyitno, 'The effectiveness of using blended learning models against vocational education student learning motivation', Int. J. Adv. Trends Comput. Sci. Eng., vol. 9, no. 5, pp. 7964 7968, 2020, doi: 10.30534/ijatcse/2020/151952020.

[14] R. Rabiman, M. Nurtanto, and N. Kholifah, 'Design and development E-learning system by learning management system (Lms) in vocational education', Int. J. Sci. Technol. Res., vol. 9, no. 1, pp. 1059-1063, 2020.

[15] M. Pavlova, Technology and Vocational Education for Sustainable Development. Queensland: Springer Science Business Media B.V., 2009.

[16] S. Sharma, 'Descriptive Statistics', May 2019.

[17] T. Nemoto and D. Beglar, 'Developing Likert-Scale Questionnaires', JALT2013 Conf. Proc., p. 8, 2014.

[18] P. Sudira, Paradigma baru pembelajaran vokasional era industri 4.0. Yogyakarta: UNY PRESS, 2020.

[19] M. Phillips, Digital Technology, School and Teachers' Workplace Learning. London: Springer Nature, 2016. 
[20] G. Falloon, 'From digital literacy to digital competence: the teacher digital competency (TDC) framework', Educ. Technol. Res. Dev., vol. 68, no. 5, pp. 2449-2472, 2020, doi: 10.1007/s11423-020-09767-4.

[21] F. P. Tulinayo, P. Ssentume, and R. Najjuma, 'Digital technologies in resource constrained higher institutions of learning: a study on students' acceptance and usability', Int. J. Educ. Technol. High. Educ., vol. 15, no. 1, 2018, doi: 10.1186/s41239-018-0117-y.

[22] E. Creely and D. Henriksen, 'Creativity and Digital Technologies', Encycl. Educ. Innov., pp. 1-6, 2019, doi: 10.1007/978-981-13-2262-4_143-1.

[23] B. Moore and T. Stanley, 'Critical Thinking and Formative Assessments: Increasing the Rigor in Your Classroom', Critical Thinking and Formative Assessments. Eye On Education, Larchmont, 2010, doi: 10.4324/9781315856261. 